\title{
Assessment of left atrial function in dogs with myxomatous mitral valve disease by biplane simpson's method
}

\author{
[Avaliação da função atrial esquerda em cães com degeneração mixomatosa de valva mitral pelo \\ método Simpson biplanar] \\ M.R. Coelho ${ }^{1}$, R.A.L. Muzzi $i^{3}$, C.B. Abreu ${ }^{1}$, T. Schulien ${ }^{2}$, L.A.L. Muzzi $i^{3}$, \\ L.E.D. Oliveira ${ }^{1}$, M. Cherem $^{4}$ \\ ${ }^{1}$ Aluno de pós-graduação - Universidade Federal de Lavras - Lavras, MG \\ ${ }^{2}$ Universidade Vale do Rio Verde - Unincor - Três Corações, MG \\ ${ }^{3}$ Universidade Federal de Lavras, MG \\ ${ }^{4}$ Hospital Vaz Monteiro - Lavras, MG
}

\begin{abstract}
The relationship between the diameter of the left atrium (LA) and aorta (Ao) is considered as a prognostic factor in chronic mitral valve disease. As the left atrium is a three-dimensional structure, methods based on measurement of the chamber volume can be more accurate than linear methods.The aim of this study was to assess the feasibility of measuring LA volume with 2D echocardiography using the biplane modified Simpson (SIMP) method in 33 dogs with various classes of myxomatous mitral valve disease (MMVD), as well as to present values of LA function using the atrial diastolic and systolic volume indices (ADVI and ASVI), cardiac index (ACI) and atrial ejection fraction (AEF). We observed agreement among the LA/Ao ratio and the atrial volume indices (ADVI and ASVI) and the ACI, suggesting that the values of the variables increase as the LA/Ao ratio increases due to atrial remodeling that accompanies MMVD progression. The data demonstrated a good assessment of atrial function, allowing a better understanding of LA's role in the pathophysiology of MMVD.
\end{abstract}

Keywords: dogs, valvulopathy, 2D echocardiography, LA volume

\section{RESUMO}

A relação entre o diâmetro átrio esquerdo (AE) e da aorta (Ao) é considerada como fator prognóstico na doença crônica de valva mitral. Como o átrio esquerdo é uma estrutura tridimensional, os métodos baseados na mensuração de volume da câmara podem ser mais precisos que os métodos lineares. $O$ objetivo deste estudo foi avaliar a viabilidade da mensuração do volume do AE com a ecocardiografia bidimensional, sendo usado o método Simpson biplanar em 33 cães com diversas classes da degeneração mixomatosa de valva mitral (DMVM), bem como apresentar valores de função do AE utilizando-se os índices de volumes atriais diastólico e sistólico (iVdA e iVsA), o índice cardíaco atrial (iCA) e a fração de ejeção atrial (FEA). Observou-se uma concordância entre a relação AE/Ao e os índices de volume atrial (iVdA e iVsA) e o iCA, o que sugere que os valores das variáveis aumentam à medida que a relação AE/Ao aumenta, devido à remodelação atrial que acompanha a progressão da DMVM. Os dados demonstram uma boa avaliação da função atrial e permitem uma melhor compreensão do papel do $A E$ na fisiopatologia da DMVM.

Palavras-chave: cão, valvulopatia, ecocardiografia bidimensional, volume atrial esquerdo

\section{INTRODUCTION}

Myxomatous mitral valve disease (MMVD) is the most common heart disease in dogs (Lewis et al., 2011). The size of the left atrium (LA) has been shown to be one of the most important predictors of disease severity in dogs with MMVD (Wesselowski et al., 2014).

Recebido em 31 de outubro de 2016

Aceito em 6 de setembro de 2017

E-mail: marianacoelhorc@gmail.com 
Atrial function is usually characterized by three phases: a reservoir phase during ventricular contraction, one conduit phase during early ventricular diastole and a booster pump phase during atrial contraction (Gutman et al., 1983). These phases are responsible for contributing to the appropriate left ventricular filling as well as the cardiovascular performance. Thus, an increase in the LA size, as occurs in MMVD, can result in impaired atrial function (Caivano et al., 2016). Three commonly used methods for evaluation of LA volume are the biplane area length (AL), the biplane modified Simpson (SIMP), and the prolate ellipse (PE) methods (Jiamsripong et al., 2008). The SIMP being preferred by most physicians, as it relies on fewer geometrical assumptions when compared to the previous methods (Lupu et al., 2014).

Several studies have been conducted in humans to assess left atrial function using this echocardiographic tool, but in veterinary medicine, no method has been standardized for LA volume measurements, and to date there is no reference values for LA volume obtained by the SIMP method in MMVD dogs.

The objective of this study is to assess the feasibility of measuring LA volumes with 2D echocardiography using the modified biplane Simpson (SIMP) method, as well as to present values for LA volumes in dogs with MMVD.

\section{MATERIALS AND METHODS}

The study population consisted of $33 \mathrm{dogs}$ in clinical routine at the Cardiology Service, which were divided into the control group consisted of eight healthy animals, and the animals affected with MMVD were divided according to the classification proposed by Atkins et al, (2009): group B1 included ten animals with class B1 MMVD (MMVD without cardiac remodeling), group B2 included eight animals with class B2 MMVD (MMVD, cardiac remodeling without congestive heart failure $(\mathrm{CHF})$ and group $\mathrm{C}$ consisted of seven animals with classes $\mathrm{C}$ MMVD (animals with MMVD and CHF). The owner's consent was obtained prior to inclusion in the study. The study protocol complied with the institutional ethics committee's guidelines for animal use under protocol number 029/2010. Other cardiac abnormalities not related to MMVD were excluded, including pulmonary hypertension secondary to mitral and tricuspid degeneration. Animals treated with pimobendan were excluded from the study, because this drug promotes improved systolic function, thus it has positive inotropic property (Fabretti and Beloni, 2012), which could contribute to normal myocardial deformation values and mask possible changes between groups. However, the animals in groups B2 and C were being treated with benazepril (15), furosemide (11), spironolactone (8) and omega-three (12).

Echocardiographic studies were performed using echocardiographic equipment (MyLab 40 Esaote $^{\circledR}$, Italy) with $4-10 \mathrm{~Hz}$ multi-frequency electronic sector scanning transducers. All examinations were performed without sedation and with the animals gently restrained. The conventional echocardiographic variables included measurements of the diameter of the LA and aorta (Ao) and the LA/Ao ratio using a right parasternal short axis on the plane of the great vessels (Hansson et al., 2002). Images were generated, and conventional echocardiography evaluations were performed as recommended by Thomas et al. (1993). For the left atrial evaluation, measurements were taken using the Simpson's method (SIMP) on the left apical twoand four-chambers views, at the end of ventricular systole, to calculate the atrial systolic and diastolic volumes indices (ASVI and ADVI), atrial ejection fraction (AEF) and atrial cardiac output index (ACI), as recommended by the American Society of Echocardiography (Lang et al., 2005). The LA endocardial border was traced, and the volumes were calculated by the software package (Figure 1). The LA appendage and the pulmonary vein confluence were excluded from the LA tracings, and a line was traced between the points of the mitral annulus. The LA volumes were indexed to body surface area

The data are presented as mean \pm standard deviation (SD) when presented a normal distribution and median (range) for data without normal distribution. All data were tested for normality using the Kolmogorov-Smirnov test $(\mathrm{P}>0.05)$, and the homoscedasticity of variance was evaluated using Levene's test $(\mathrm{P}>0.05)$. The statistical analyses were performed using the statistical package IBM@ SPSS for Windows version 20.0 . 
An analysis of variance (ANOVA) was used to analyze LA/Ao ratio, and ASVI, ADVI, AEF and ACI by Simpson's method, and the means were compared using the Tukey's test when significant among classes of MMVD. For data that did not have a normal distribution, the Mann-Whitney and Kruskal-Wallis tests were used to compare the medians among groups when they were significant.
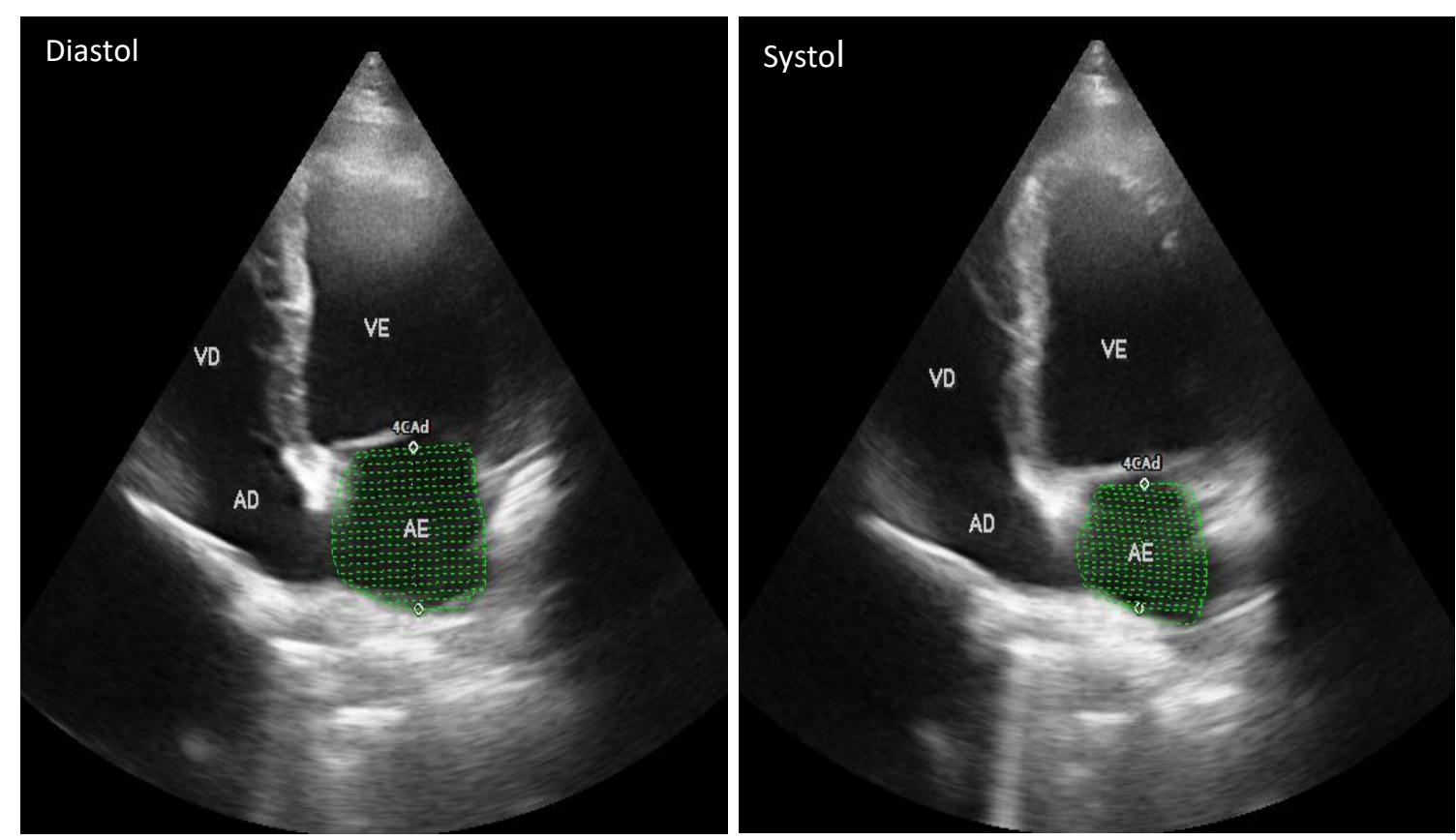

Figure 1. Two-dimensional echocardiographic images in left 4-chamber apical view, showing the measurement of the atrial volume by the Simpson's method in a dog of the control group, during systole and diastole (Cardiology service /HV - UFLA). AE - left atrium; VE - left ventricle; AD - right atrium; $\mathrm{VD}$ - right ventricle.

\section{RESULTS}

The demographic data was consisted of age (months) 111.64 \pm 42.48 , weight $(\mathrm{kg}) 9.78 \pm 5.40$, gender, being 9 males $(27.3 \%)$ and 24 females $(72.7 \%)$, and the breeds were Crossbreed $n=2$ $(6.1 \%)$, Beagle $n=8(24.2 \%)$, Poodle $n=6$ $(18.2 \%)$, Dachshund $\mathrm{n}=6(18.2 \%)$, Yorkshire Terrier $n=2(6.1 \%)$, Basset Hound $n=1(3 \%)$, Blue Hiller $\mathrm{n}=1(3 \%)$, Cocker Spaniel $\mathrm{n}=1$ $(3 \%)$, Brazilian Terrier $n=1(3 \%)$, Pekingese $n=$
1 (3\%), Pinscher $\mathrm{n}=1 \quad(3 \%)$, Miniature Schnauzer $n=1(3 \%)$, Shih Tzu $n=1(3 \%)$ and West Highland White Terrier $n=1(3 \%)$.

The conventional echocardiography data (Table 1) are presented as the mean and standard deviation for data with normal distribution and median and range for data without normal distribution. Table 2 shows the variables for the left atrial function obtained using Simpson's method based on the MMVD classification. 
Table 1 . The variables obtained by conventional echocardiography for the groups evaluated $(n=33)$

\begin{tabular}{|c|c|c|c|c|c|}
\hline \multirow[b]{2}{*}{ Variables } & \multicolumn{4}{|c|}{ DMVD class } & \multirow[b]{2}{*}{$P$ value } \\
\hline & $\begin{array}{c}\text { Control } \\
(\mathrm{n}=8)\end{array}$ & $\begin{array}{c}\mathrm{B} 1 \\
(\mathrm{n}=10)\end{array}$ & $\begin{array}{c}\mathrm{B} 2 \\
(\mathrm{n}=8)\end{array}$ & $\begin{array}{c}C \\
(n=7)\end{array}$ & \\
\hline EF VE (\%) & $62.33 \pm 7.61 \mathrm{bc}$ & $56.00 \pm 15.77 \mathrm{bc}$ & $75.71 \pm 6.96 \mathrm{a}$ & $70.33 \pm 14.62 \mathrm{ab}$ & $<0.001$ \\
\hline $\mathrm{FS}(\%)$ & $37.00 \pm 2.68 \mathrm{bc}$ & $30.75 \pm 13.32 \mathrm{c}$ & $42.29 \pm 8.26 \mathrm{a}$ & $40.67 \pm 12.76 \mathrm{ab}$ & $0.013^{*}$ \\
\hline LA/Ao ratio & $1.18 \pm 0.08 \mathrm{c}$ & $1.04 \pm 0.06 \mathrm{c}$ & $1.60 \pm 0.13 \mathrm{~b}$ & $2.60 \pm 0.16 \mathrm{a}$ & $<0.01^{*}$ \\
\hline Mitral E (m/s) & $1.13(0.41) b$ & $0.71(0.52) \mathrm{c}$ & $1.05(1.27) \mathrm{b}$ & 1.49 (1.67) a & $<0.01^{\#}$ \\
\hline Mitral A (m/s) & $0.66 \pm 0.15$ & $0.68 \pm 0.18$ & $0.80 \pm 0.19$ & $0.77 \pm 0.28$ & 0.197 \\
\hline Mitral E/A ratio & $1.55(0.28) \mathrm{ab}$ & $1.22(0.85) \mathrm{c}$ & $1.47(1.42) b$ & $1.80(1.14) \mathrm{a}$ & $<0.01^{\#}$ \\
\hline $\begin{array}{l}\text { Pulmonary flow } \\
(\mathrm{m} / \mathrm{s})\end{array}$ & $0.90(0.02) \mathrm{a}$ & $0.78(0.38) b$ & $0.73(0.57) \mathrm{c}$ & $0.53(0.49) \mathrm{c}$ & $<0.01^{\#}$ \\
\hline Aortic flow $(\mathrm{m} / \mathrm{s})$ & $1.22(0.16) \mathrm{a}$ & $0.84(0.58) b$ & $1.01(0.71) b$ & $0.75(0.15) \mathrm{c}$ & $<0.01^{\#}$ \\
\hline Tricuspid E & $0.74(0.04)$ & $0.74(0.41)$ & $0.66(0.36)$ & $0.57(1.07)$ & 0.119 \\
\hline Tricuspid A & $0.43(0.02)$ & $0.48(0.30)$ & $0.42(0.23)$ & $0.41(0.50)$ & 0.624 \\
\hline $\operatorname{IVRT}(\mathrm{m} / \mathrm{s})$ & $39.00(5.00) \mathrm{b}$ & $51.00(37.00) \mathrm{a}$ & $43.00(45.00) \mathrm{b}$ & $22.00(35.00) \mathrm{c}$ & $<0.01^{\#}$ \\
\hline
\end{tabular}

Values presented as the mean \pm SD for data with normal distribution and median (range) for data without normal distribution.

Control $=$ healthy animals, $\mathrm{B} 1=$ animals with DMVD without cardiac remodeling, $\mathrm{B} 2=$ animals with DMVD and cardiac remodeling without $\mathrm{CHF}$, and group $\mathrm{C}=$ animals with DMVD and CHF, FE VE: Ejection fraction, FS: Fractional shortening, LA/Ao: Ratio between the diameter of the left atrium and the aorta, Mitral E: E wave of mitral valve, Mitral A: A wave of mitral valve, Tricuspid E: E wave of tricuspid valve, Tricuspid A: A wave of tricuspid valve, IVRT: isovolumetric relaxation time.

*Means followed by different letters in the same row are different using Tukey's test $(\mathrm{P}<0.01)$.

\#Means followed by different letters in the same row are different using the Mann-Whitney's test $(\mathrm{P}<0.05)$.

Tabela 2. Values ( mean \pm SD) of left atrial function indices obtained by Simpson's method in relation to MMVD classification in dogs $(n=33)$

\begin{tabular}{ccccc}
\hline Variable evaluated & Control & B1 & B2 & C \\
\hline AEF $(\%)$ & $63.33 \pm 5.58 \mathrm{a}$ & $63.75 \pm 4.29 \mathrm{a}$ & $62.81 \pm 4.04 \mathrm{a}$ & $37.21 \pm 4.64 \mathrm{~b}$ \\
ADVI $\left(\mathrm{mL} / \mathrm{m}^{2}\right)$ & $21.12 \pm 2.69 \mathrm{~b}$ & $22.24 \pm 5.33 \mathrm{~b}$ & $18.64 \pm 4.12 \mathrm{~b}$ & $84.13 \pm 18.56 \mathrm{a}$ \\
ASVI $\left(\mathrm{mL} / \mathrm{m}^{2}\right)$ & $7.20 \pm 1.33 \mathrm{~d}$ & $8.67 \pm 2.26 \mathrm{c}$ & $13.81 \pm 5.20 \mathrm{~b}$ & $54.23 \pm 17.36 \mathrm{a}$ \\
$\mathrm{ACI}\left(\mathrm{L} / \mathrm{min} / \mathrm{m}^{2}\right)$ & $0.54 \pm 0.19 \mathrm{~b}$ & $0.35 \pm 0.21 \mathrm{c}$ & $0.24 \pm 0.04 \mathrm{c}$ & $0.76 \pm 0.24 \mathrm{a}$ \\
\hline
\end{tabular}

a, b Means followed by lowercase letters in the same row differ using the Tukey's test $(\mathrm{P}<0.05)$.

AEF: Atrial ejection fraction; ADVI: atrial diastolic volume index; ASVI: atrial systolic volume index; ACI: atrial cardiac index, Control = healthy animals, B1 = animals with DMVD without cardiac remodeling, B2 = animals with DMVD and cardiac remodeling without CHF, and group $\mathrm{C}=$ animals with DMVD and CHF.

\section{DISCUSSION}

In the present study, the Simpson's method was shown to be adequate, rapid and easily applicable for evaluating the left atrial function by generating values for the atrial diastolic and systolic volume indices, atrial cardiac index and atrial ejection fraction in dogs with MMVD. These values of LA function might provide a better basis for assessing LA size than linear LA dimensions when examining dogs with heart disease as also observed by Hölmer et al. (2016).
The dogs used in this study were randomly selected according to the routine cardiology institution, which explains the variation between age, breed and sex. Thus, although described in the literature that male are more affected (Atkins et al., 2009), in our study the number of females was higher than males in all groups. Furthermore, data relating to the weight of the animals showed an mean of less than $20 \mathrm{~kg}$ of body weight, which agrees with the literature since the MMVD is more frequent in dogs of small breeds and more than eight years old (Atkins et al., 2009; Borgarelli and Buchanan, 2012). 
In this study, the LA/Ao ratio values increased as a function of the MMVD class and progression, as expected. According to Schober and Fuentes (2001), IVRT can yield lower values given an increased preload and left atrial pressure in addition to an increased heart rate, which also contributes to a reduction in this variable. This effect was also observed in our study, with group $\mathrm{C}$ having a higher LA/Ao ratio and, thus, pronounced atrial remodeling, besides a lower IVRT.

In the control group, the value of the mitral $\mathrm{E}$ wave was higher than in the $\mathrm{B} 1$ group, but below the normal values of $1.20 \mathrm{~m} / \mathrm{s}$. However, there was a progressive increase in this variable in groups $\mathrm{B} 1, \mathrm{~B} 2$ and $\mathrm{C}$, which is expected in critically ill animals, wherein the prognosis is worse due to the increase of mitral regurgitation (MR) (Schober et al., 2010).

In the present study, there was an agreement between the LA/Ao ratio and the atrial volume indices ADVI and ASVI and the ACI. This result suggests that the values of the variables analyzed increases as the value of the LA/Ao ratio increases too. This fact can be explained by the deterioration of the MR and, consequently, the atrial remodeling that accompanies DMVD progression. The increased size of the LA produces an increased preload and, thus, an increase in the previously cited atrial volume indices, which is consistent with findings in the literature (Nakamura et al., 2014). In the study of Moustafa et al. (2011), values for atrial volume index with a gradual increase in the severity of the regurgitation of MMVD in humans were also observed. Moreover, a negative relation between the LA/Ao ratio and AEF was observed, as reported in a study by Tidholm et al. (2013), in which they had used real-time 3D echocardiography to evaluate the AEF in dogs with DMVD and observed that the AEF values decreased as the values of the LA/Ao ratio increased.

The present study has some limitations including its non-invasive design and that the tests were performed on pets and, thus, no invasive procedures or examinations were performed to obtain hemodynamic data to aid in defining the body homeostasis of the animals evaluated. In addition, because the study was conducted using animals that routinely visited the clinic, it was difficult to use animals that had not received any treatment. Accordingly, there is no way to assess whether these medications interfered with the Simpson's method measurements.

Another issue that has also been reported in other studies (Schwarzwald et al., 2009; Silva et al., 2013) is that the data obtained in our study may not be applicable to all clinical situations because of the differences that exist between the echocardiography devices, software and equipment used and the image quality obtained, which are factors that may affect the values and variability of the data.

In conclusion, this study showed that the left atrial function can be evaluated using the modified biplane Simpson (SIMP) method. The data presented here provide new insights into variables that are determinants of atrial function, allowing for a more complete quantification of atrial function and an increased understanding of the role that the LA plays in the pathophysiology of MMVD. However, more studies are needed to standardize the modified biplane Simpson (SIMP) method as appropriate to measure the atrial volume, and to determine whether the prognostic values of LA function by Simpson's method is superior to that of LA/Ao.

\section{ACKNOWLEDGEMENTS}

The PhD Adriana Cristina da Silva of Federal University of Lavras - UFLA, for their collaboration in the development of this work. This study was financed in part by the Research Foundation of the State of Minas Gerais [Fundação de Amparo a Pesquisa do Estado de Minas Gerais (FAPEMIG)].

\section{REFERENCES}

ATKINS, C.; BONAGURA, J.; ETTINGER, S. et al. Guidelines for the diagnosis and treatment of canine chronic valvular heart disease. J. Vet. Intern. Med., v.23, p.1142-1150, 2009.

BORGARELLI, M.; BUCHANAN, J.W. Historical review, epidemiology and natural history of degenerative mitral valve disease. $J$. Vet. Cardiol., v.14, p.93-101, 2012.

CAIVANO, D.; RISHNIW, M.; PATATA, V. et $a l$. Left atrial deformation and phasic function determined by 2-dimensional speckle tracking echocardiography in healthy dogs. J. Vet. Cardiol., v.18, p.146-155, 2016. 
FABRETTI, A.K.; BELONI, S.N.E. Uso do pimobendan no tratamento da insuficiência cardíaca - revisão de literatura. Rev. Clin. Vet., v.97, p.48-54, 2012.

GUTMAN, J.; FRACP, B.S.; WANG, Y.S. et al. Normal left atrial function determined by 2dimensional echocardiography. Am. J. Cardiol., v.15, p.336-340, 1983.

HANSSON, K.; HÄGGSTROM, J.; KVART, C.; LORD, P. Left atrial to aortic root indices using two-dimensional and M-mode echocardiography in cavalier King Charles spaniels with and without left atrial enlargement. Vet. Radiol. Ultrasound, v.43, p.568-575, 2002.

HÖLLMER, M.; WILLESEN, J.L.; TOLVER, A.; KOCH, J. Comparison of four echocardiography methods to determine left atrial size in dogs. J. Vet. Cardiol., v.18, p.137145, 2016.

JIAMSRIPONG, P.; HONDA, T.; REUSS, C.S. et al. Three methods for evaluation of left atrial volume. Eur. J. Echocardiogr., v.9, p.351-355, 2008.

LANG, R.M.; BIERIG, M.; DEVEREUX, R.B. et al. Recommendations for chamber quantification: a report from the American Society of Echocardiography's Guidelines and Standards Committee and the Chamber Quantification Writing Group, developed in conjunction with the European Association of Echocardiography, a branch of the European Society of Cardiology. J. Am. Soc. Echocardiogr., v.18, p.1440-1463, 2005.

LEWIS, T.; SWIFT, S.; WOOLLIAMS, J.A.; BLOTT, S. Heritability of premature mitral valve disease in Cavalier King Charles spaniels. Vet. J., v.188, p.73-76, 2011.

LUPU, S.; MITRE, A.; DOBREANU, D. Left atrium function assessment by echocardiography - physiological and clinical implications. Med. Ultrasson., v.16, p.152-159, 2014.

MOUSTAFA, S.E.; ALHARTHI, M.; KANSAL, M. et al. Global left atrial dysfunction and regional heterogeneity in primary chronic mitral insufficiency. Eur. J. Echocardiogr., v.12, p.384$393,2011$.
NAKAMURA, K.; OSUGA, T.; MORISHITA, K. et al. Prognostic value of left atrial function in dogs with chronic mitral valvular heart disease. J. Vet. Intern. Med., v.28, p.1746-1752, 2014.

SCHOBER, K.E.; FUENTES, V.L. Effects of age, body weight, and heart rate on transmitral and pulmonary venous flow in clinically normal dogs. Am. J. Vet. Res., v.62, p.1447-1454, 2001.

SCHOBER, K.E.; HART, T.M.; STERN, J.A. et al. Detection of congestive heart failure in dogs by Doppler echocardiography. J. Vet. Intern. Med., v.24, p.1358-1368, 2010.

SCHWARZWALD, C.C.; SCHOBER, K.E.; BERLI, A.S.; BONAGURA, J.D. Left ventricular radial and circumferential wall motion analysis in horses using strain, strain rate, and displacement by 2D speckle tracking. J. Vet. Intern. Med., v.23, p.890-900, 2009

SILVA, A.C.; MUZZI, R.A.; OBERLENDER, $\mathrm{G}$. et al. Longitudinal strain and strain rate by two-dimensional speckle tracking in non-sedated healthy cats. Res. Vet. Sci., v.95, p.1175-1180, 2013.

THOMAS, W.P.; GABER, C.E.; JACOBS, G.J. et al. Recommendations for standards in transthoracic two-dimensional echocardiography in the dog and cat. Echocardiography Committee of the Specialty of Cardiology, American College of Veterinary Internal Medicine. J. Vet. Intern. Med., v.7, p.247-252, 1993.

TIDHOLM, A.; HÖGLUND, K.; HÄGGSTRÖM, J. et al. Left atrial ejection fraction assessed by real-time 3- dimensional echocardiography in normal dogs and dogs with myxomatous mitral valve disease. J. Vet. Intern. Med., v.27, p.884-889, 2013.

WESSELOWSKI, S.; BORGARELLI, M.; BELLO, N.M.; ABBOTT, J. Discrepancies in identification of left atrial enlargement using left atrial volume versus left atrial-to-aortic root ratio in dogs. J. Vet. Intern. Med., v.28, p.1527-1533, 2014. 